\title{
Cutting Edge of Brain Natriuretic Peptide (BNP) Research - The Diversity of BNP Immunoreactivity and Its Clinical Relevance -
}

\author{
Koichiro Kuwahara, MD, PhD; Yasuaki Nakagawa, MD, PhD; Toshio Nishikimi, MD, PhD
}

\begin{abstract}
Brain (or B-type) natriuretic peptide (BNP) is a cardiac hormone produced in the heart and an established biochemical marker for heart failure (HF) because the level in plasma increases in proportion to disease severity. Recently, the diversity of BNP molecular forms in the peripheral circulation, which includes mature $\mathrm{BNP}\left(\mathrm{BNP}_{1-32}\right)$ and its metabolites $\left(\mathrm{BNP}_{3-32}, \mathrm{BNP}_{4-32}\right.$, and $\left.\mathrm{BNP}_{5-32}\right)$, was demonstrated. Moreover, studies showed that unprocessed BNP prohormone (proBNP) is also secreted from the heart, and its secretion is increased in patients with HF. Interestingly, $\mathrm{BNP}_{1-32}$, its metabolites, and proBNP are all detected as immunoreactive BNP by the currently available BNP assay system. Current N-terminal proBNP (NT-proBNP) assay systems also can react to both NT-proBNP and proBNP. In addition, the N-terminal region of proBNP and NT-proBNP are often O-glycosylated, which may result in underestimation of total NT-proBNP level, which includes both glycosylated and non-glycosylated NT-proBNP, by the NT-proBNP assay system. More recently, we have shown that miR30-GALNT-dependent $O$-glycosylation in the N-terminal region of proBNP affects the processing of proBNP and contributes to its secretion from the heart. The level of proBNP relative to BNP (proBNP/BNP ratio) in the coronary sinus is higher in patients with more severe HF. The proBNP/BNP ratio and the deglycosylated NT-proBNP level may be new and clinically useful biomarkers of HF.
\end{abstract}

Key Words: BNP; Heart failure; NT-proBNP; O-glycosylation; proBNP

$\mathbf{T}$ he natriuretic peptide family consists of 3 endogenous peptides: atrial natriuretic peptide (ANP), brain (or B-type) natriuretic peptide (BNP), and C-type natriuretic peptide (CNP). All 3 peptides were discovered by Kangawa, Matsuo and their colleagues. ${ }^{1-3}$ Following the discovery of ANP in atrial tissue extract in 1983-1984, 1,4,5 BNP was isolated from porcine brain in 1988. ${ }^{2}$ Nonetheless, both BNP and ANP are primarily expressed in and secreted from cardiac tissue. They then preferentially bind to natriuretic peptide receptor-A (NPRA, or guanylyl cyclase-A), which induces generation of the intracellular second messenger cyclic guanosine monophosphate (cGMP) in their target cells. Through its pleiotropic effects, this system plays important roles in the regulation of blood pressure and body fluid volume, leading to the clinical application of both ANP and BNP to the treatment of patients with heart failure (HF). Notably, the plasma BNP level is dramatically increased in proportion to disease severity in patients with $\mathrm{HF}$, and it is currently an established biomarker for heart disease listed in guidelines published worldwide. ${ }^{6,7}$ Administration of carperitide or nesiritide, which are recombinant ANP and BNP, respectively, is able to ameliorate the hemodynamic conditions and symptoms in patients with HF, despite the high levels of BNP already circulating in these patients. It appears the efficacy of endogenous BNP is lower in these patients than would be expected given the high levels of immunoreactive BNP. This discrepancy reflects the presence of a variety of BNP-related peptides circulating in these patients. In this review, we will discuss the diversity of circulating BNPrelated peptides and their clinical relevance.

\section{Does the Currently Available BNP Immunoreactivity System Measure Only BNP1-32?}

Plasma BNP levels are increased in proportion to disease severity in patients with HF. ${ }^{\mathbf{8} 9}$ Moreover, it appears they are also increased under other pathological conditions, including myocardial infarction, ${ }^{10}$ cardiac hypertrophy, ${ }^{11}$ and pulmonary hypertension. ${ }^{12}$ With the BNP assay systems (e.g., Shionogi, Biosite) currently in use, BNP is sandwiched by 2 antibodies. One is the capture antibody, which recognizes the C-terminus of BNP, and the other is the detection antibody, which recognizes its ring structure. This assay system thus evaluates BNP levels independently of the length of the $\mathrm{N}$-terminal segment extending from the ring structure. This means the currently available BNP assay also detects proBNP, as well as any truncated BNP metabolites if they are present in the plasma. Indeed, Hawkridge et $a{ }^{13}$ reported that mass spectrometry after extraction of

Received July 23, 2018; accepted July 31, 2018; released online August 21, 2018

Department of Cardiovascular Medicine, Shinshu University School of Medicine, Matsumoto (K.K.); Department of Cardiovascular Medicine, Kyoto University Graduate School of Medicine, Kyoto (Y.N., T.N.); and Department of Internal Medicine, Wakakusa-Tatsuma Rehabilitation Hospital, Daito (T.N.), Japan

Mailing address: Koichiro Kuwahara, MD, PhD, Department of Cardiovascular Medicine, Shinshu University School of Medicine, 3-1-1 Asahi, Matsumoto 390-8621, Japan. E-mail: kkuwah@shinshu-u.ac.jp

ISSN-1346-9843 All rights are reserved to the Japanese Circulation Society. For permissions, please e-mail: cj@j-circ.or.jp 
A

Immunoreactive BNP

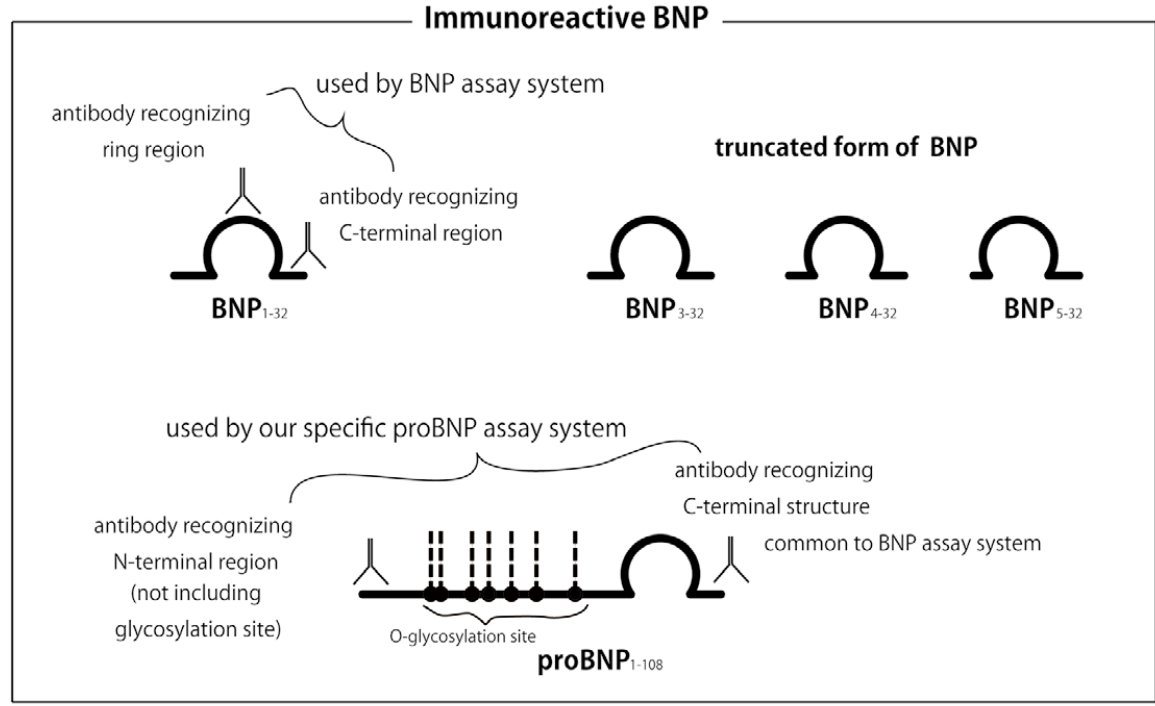

B

Elecsys I

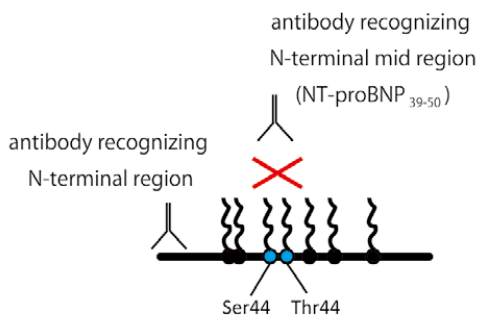

Elecsys II
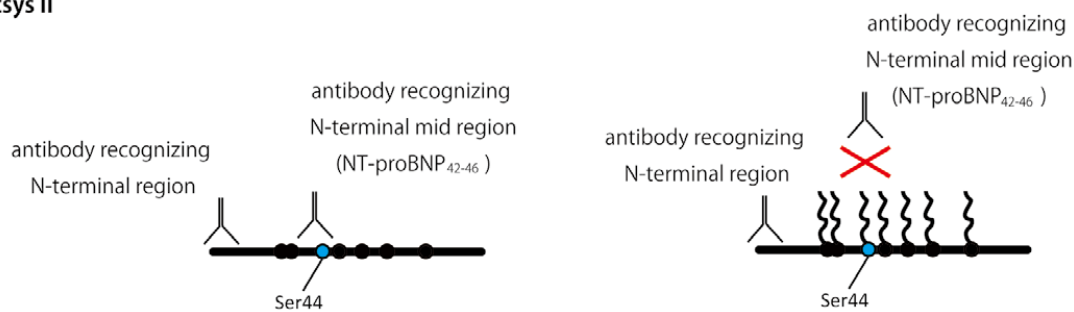

Figure 1. Immunoreactive BNP comprises mature BNP ${ }_{1-32}$, truncated forms of $B N P$ and proBNP. (A) The currently available BNP assay system uses 2 antibodies, which respectively recognize the ring and C-terminal regions of BNP. Consequently, this system recognizes mature BNP1-32, truncated forms of BNP and proBNP. Our recently developed proBNP-specific assay system uses an antibody common to BNP assays that recognizes the $\mathrm{C}$-terminal region and an antibody that recognizes an area of the $\mathrm{N}$-terminal region that does not contain O-glycosylation sites. This enables us to specifically measure proBNP without the influence of O-glycosylation. (B) Conceptual schemas for an NT-proBNP assay system. The Elecsys I assay system uses an antibody that recognizes NT-proBNP39-50, which contains 2 glycosylation sites, Ser44 and Thr48. The Elecsys II system uses an antibody that recognizes NT-proBNP42-46, which contains one glycosylation site, Ser44. NT-proBNP glycosylated at Ser44 and/or Thr48 is not detected by Elecsys I (Upper), and NT-proBNP glycosylated at Ser44 is not detected by Elecsys II (Lower). BNP, brain (B-type) natriuretic peptide.

plasma using several chromatography techniques detected no mature $\mathrm{BNP}_{1-32}$, arguing that there is no endogenous $\mathrm{BNP}_{1-32}$ in the plasma of patients with severe $\mathrm{HF}$, despite higher plasma immunoreactive BNP levels. A later study using mass spectrometry techniques that carefully dealt with plasma during the extraction process so as not to lose the $\mathrm{BNP}_{1-32}$ activity showed that although $\mathrm{BNP}_{1-32}$ was present, its level was low, and several truncated $\mathrm{BNP}$ forms $\left(\mathrm{BNP}_{3-32}\right.$, $\mathrm{BNP}_{4-32}$, and $\mathrm{BNP}_{5-32}$ ) were also detected. ${ }^{14}$ In addition, Miller et al $^{\mathbf{1 5}}$ used a quantitative mass spectrometry immunoassay to show that $\mathrm{BNP}_{1-32}$ levels are low, and that $\mathrm{BNP}_{3-32}, \mathrm{BNP}_{4-32}$, and $\mathrm{BNP}_{5-32}$ are also present in plasma from HF patients. They also showed that there are significant relationships between the plasma levels of the truncated 
BNP forms and levels of clinical BNP. Once in the plasma, depeptidyl peptidase IV (DPP IV) enzymatically cleaves the $2 \mathrm{~N}$-terminal amino acids (serine-proline) from $\mathrm{BNP}_{1-32}$ to generate the truncated form, BNP3-32, ${ }^{16}$ the levels of which are increased in patients with HF. ${ }^{17}$ Moreover, other aminopeptidases in the peripheral circulation may further digest the N-terminal region of $\mathrm{BNP}_{1-32}$ and/or $\mathrm{BNP}_{3-32}$. These findings indicate that several molecular forms of BNP circulate in the plasma of patients with HF, and the BNP measurement system currently used to measure mature $\mathrm{BNP}_{1-32}$ cross-reacts other BNP forms with shorter N-terminal segments, including $\mathrm{BNP}_{3-32}$, $\mathrm{BNP}_{4-32}$, and $\mathrm{BNP}_{5-35}$ (Figure 1A).

As mentioned, BNP exerts its physiological effects on target cells via NPR-A-dependent cGMP production. The precise biological activities of the various molecular forms of $\mathrm{BNP}$ remain unclear, though $\mathrm{BNP}_{1-32}$ and $\mathrm{BNP}_{3-32}$ are reported to have similar bioactivity in cardiacmyocytes. ${ }^{18}$ Likewise, the ability of recombinant mouse $\mathrm{BNP}_{7-32}$ to induce in vitro cGMP production is reportedly similar to that of mouse $\mathrm{BNP}_{1-32 .}{ }^{19}$ It may be, therefore, that other BNP forms with shorter N-terminal segments have biological activity similar to that of $\mathrm{BNP}_{1-32}$.

\section{Presence of the BNP Precursor proBNP1-108 in the Circulation: Increased proBNP in HF Patients}

The BNP precursor peptide, proBNP, is thought to be cleaved to $\mathrm{BNP}_{1-32}$ and $\mathrm{N}$-terminal (NT)-proBNP within cardiac myocytes, leading to secretion of $\mathrm{BNP}_{1-32}$ and NTproBNP into the peripheral circulation. However, several recent studies demonstrated that a certain amount of proBNP is itself also secreted from cardiomyocytes and circulates in human plasma, and that levels of proBNP are increased in HF patients. ${ }^{17,20-23}$ We evaluated plasma and tissue levels of proBNP using gel-filtration high-performance liquid chromatography (HPLC) combined with a direct chemiluminescent BNP immunoassay, ${ }^{24}$ which showed a high and a low molecular weight (LMW) peak of BNP immunoreactivity, corresponding to proBNP and mature $\mathrm{BNP}_{1-32}$, respectively. We therefore developed a proBNP-specific measurement system, which uses 2 antibodies, BC203 (capture antibody) and 18H5 (detection antibody), which respectively recognize the C-terminal and N-terminal (aa13-20) regions of proBNP (Figure 1A). ${ }^{25}$ Importantly, because the affinities of the signal antibodies in the proBNP and BNP assay systems are the same, we are able to accurately measure the proBNP/BNP ratio in plasma. Using these 2 assay systems, we measured plasma proBNP and BNP in healthy controls and showed that the proBNP/BNP ratio in plasma of healthy controls was approximately $60-70 \%$, indicating that the major molecular form of plasma BNP is proBNP in healthy controls. Levels of both proBNP and mature BNP are markedly elevated in HF patients, and the magnitude of the increase reflects the severity of the patient's condition. ${ }^{25}$

Regarding the biological activity of proBNP, Liang et al reported that recombinant proBNP has much less bioactivity than BNP in human endothelial and vascular smooth muscle cells. ${ }^{26} \mathrm{We}$ also found that proBNP is much less able to induce cGMP production than BNP in cardiac myocytes and fibroblasts cultured from neonatal rats. ${ }^{27}$ Consequently, when biologically less active proBNP is increased in HF patients, it may lead to decompensation because of the attenuated cardioprotective effect, which does not match the full effect estimated from immunoreac- tive BNP level. Indeed, proBNP is thought to be one of the causes for the "BNP paradox" (i.e., administration of exogenous natriuretic peptide effectively improves hemodynamics and clinical symptoms in patients with $\mathrm{HF}$, despite apparently high levels of circulating BNP). ${ }^{28}$

\section{Glycosylation of proBNP and NT-proBNP}

In 2006, Schellenberger et $\mathrm{a}^{29}$ reported that the $\mathrm{N}$-terminal region of human proBNP is glycosylated (Figure 2). Their Western blot analysis showed that proBNP isolated from the plasma of HF patients migrated as a diffuse band centered around $25 \mathrm{kDa}$, and that the band was reduced to $12 \mathrm{kDa}$ by treatment with an $O$-glycosydase. In addition, using tryptic mapping and liquid chromatography-mass spectrometry, they showed that $\mathrm{CHO}$ cell-expressed proBNP is an $O$-linked glycoprotein containing 7 glycosylation sites (Thr36, Ser37, Ser44, Thr48, Ser53, Thr58, and Thr71). Liang et $\mathrm{al}^{26}$ also reported that when plasma samples from HF patients were immunoprecipitated using an antibody against BNP, subsequent Western blot analysis using an antibody against BNP produced both a high molecular weight (HMW) band (20-22kDa) and a LMW band. Using recombinant BNP as a reference, the LMW band was identified as BNP, and it was suggested that the HMW band is proBNP and represents the larger fraction of the immunoreactive BNP material. This suggests proBNP is the major molecular form in HF patients. After treatment with a deglycosylating enzyme, the HMW band shifted towards the lower molecular weight band about $12 \mathrm{kDa}$ similar to recombinant deglycosylated proBNP, which is consistent with earlier findings and confirms that a substantial amount of human proBNP is $O$-glycosylated. Using gel-filtration HPLC combined with a direct chemiluminescent immunoassay for BNP, we similarly observed that deglycosylation shifts the peak of proBNP immunoreactivity towards a protein with a smaller molecular mass. ${ }^{25}$

Because the amino acid sequence of the $\mathrm{N}$-terminal region of proBNP is common to NT-proBNP, that peptide is also thought to be glycosylated. In fact, Seferian et al ${ }^{30}$ reported that deglycosylation shifts the peak of NT-proBNP immunoreactivity towards proteins with smaller molecular masses. From their Western blot analysis, HammererLercher et $\mathrm{al}^{31}$ reported that after deglycosylation the band corresponding to NT-proBNP from severe HF patients shifts to a lower molecular weight band corresponding to synthetic NT-proBNP. We confirmed those findings using gel-filtration HPLC analysis combined with a chemiluminescent BNP immunoassay. ${ }^{24}$ It thus appears that substantial amounts of both proBNP and NT-proBNP are $O$-glycosylated.

\section{Underestimation of Levels of NT-proBNP}

In the previously used NT-proBNP assay system (Elecsys proBNP I; Roche Diagnostics), NT-proBNP is sandwiched by 2 antibodies, a capture monoclonal antibody and a signal polyclonal antibody, recognizing NT-proBNP ${ }_{1-21}$ and NTproBNP $39-50$, respectively (Figure 1B). ${ }^{32}$ NT-proBNP $39-50$ contains 2 glycosylation sites at Ser44 and Thr48. Moreover, $O$-linked oligosaccharide attachment at those sites almost completely blocks antibody binding to the glycosylated peptides. ${ }^{31,33}$ We therefore evaluated the effect of deglycosylation on measured levels of NT-proBNP using the Elecsys proBNP I assay in HF patients and patients on 


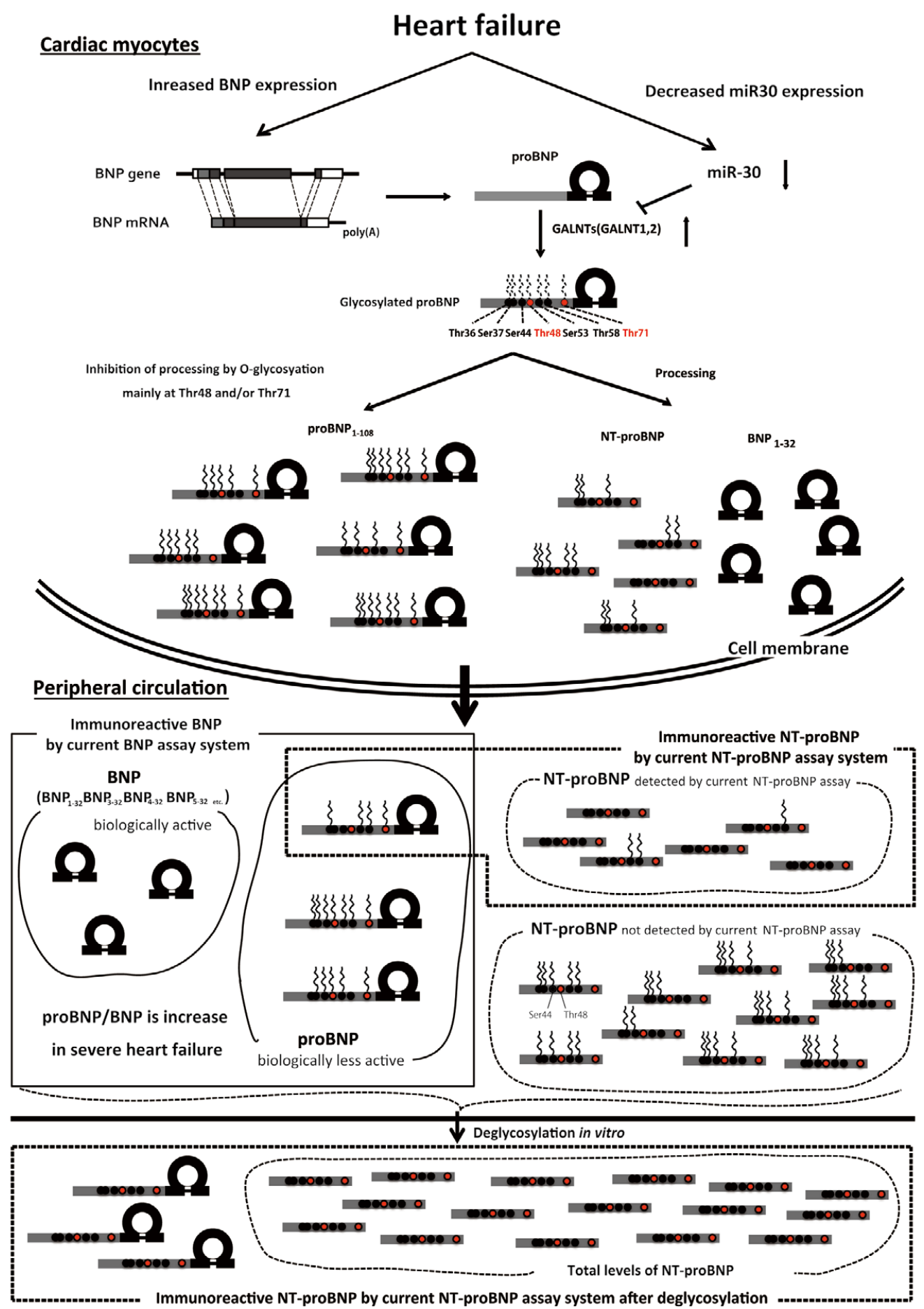

Figure 2. Our hypothesis for the regulation of production of BNP and BNP-related molecules. In heart failure, gene expression of BNP and subsequent production of proBNP are increased in the cardiomyocytes. On the other hand, decreased miR-30 facilitates O-glycosylation via increased GALNT1 and 2. Glycosylation-dependent regulation of proBNP processing affects the proBNP/BNP

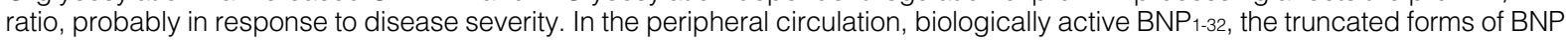
generated by various proteolytic enzymes, and the biological less active proBNP are all measured as immunoreactive BNP by currently available BNP assay system. The currently available NT-proBNP assay system underestimates the total levels of NT-proBNP because the antibody recognizes an epitope in a region containing glycosylation sites, and its binding is blocked by glycosylation. Treatment with a deglycosylation enzyme would enable estimation of the total levels of NT-proBNP, even with the currently available assay system. It should be noted that NT-proBNP assay system also cross-reacts with proBNP, despite its level being much lower than that of NT-proBNP. The precise structure of glycosylated proBNP or NT-proBNP has not yet been resolved. Consequently, this schema shows assumed structures of glycosylated proBNP and NT-proBNP that are consistent with our hypothesis. BNP, brain (B-type) natriuretic peptide. 
hemodialysis for chronic renal failure (CRF). ${ }^{32}$ Plasma BNP levels were elevated to $106 \pm 92 \mathrm{pg} / \mathrm{mL}$ in NYHA class I patients, and were also increased in NYHA classes II and III-IV patients. Plasma levels of nonglycoNT-proBNP (i.e., NT-proBNP before deglycosylation) were also increased

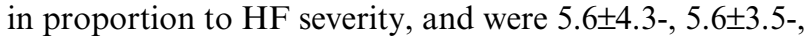
and 6.2 \pm 3.4 -fold higher than the BNP levels in NYHA classes I, II, and III-IV, respectively. On the other hand, levels of glycoNT-proBNP (i.e., NT-proBNP after deglycosylation minus the levels of nonglycoNT-proBNP) were increased to $34.7 \pm 27.7-, 33.5 \pm 16.7-$, and $30.1 \pm 27.1$-fold higher than those of BNP in the respective NYHA classes. This suggests the NT-proBNP assay system underestimates the total levels of NT-proBNP in HF patients, which includes nonglycosylated NT-proBNP and various glycosylated NT-proBNP forms. In patients on hemodialysis for CRF, BNP was increased to $367 \pm 365 \mathrm{pg} / \mathrm{mL}$ before hemodialysis. The level of NT-proBNP was increased to $7,455 \pm 8,348 \mathrm{pg} / \mathrm{mL}$, which is approximately 20 -fold higher than the BNP level. After deglycosylation treatment, the level of NT-proBNP was increased to $69,122 \pm 69,554 \mathrm{pg} / \mathrm{mL}$, approximately 200 -fold that of $\mathrm{BNP}$, suggesting that the NT-proBNP level is underestimated to a greater degree in CRF patients than in HF patients. ${ }^{32}$

We also evaluated the currently available Elecsys proBNP II (Roche Diagnostics) NT-proBNP assay system in CRF patients on hemodialysis. ${ }^{34}$ Elecsys proBNP II uses 2 antibodies, a capture antibody recognizing NT-proBNP27-31 and a detection antibody recognizing NT-proBNP42-46, which contains 1 glycosylation site at Ser44 (Figure 1B). Levels of nonglycoNT-proBNP and glycoNT-proBNP were $600 \mathrm{pg} / \mathrm{mL}$ and $1,934 \pm 1,830$, respectively, in the CRF patients, suggesting the Elecsys proBNP II assay system also underestimates the level of circulating NT-proBNP, though to a lesser degree than Elecsys I. ${ }^{\mathbf{3 4}}$ Like BNP, NT-proBNP is now an established biomarker for heart disease. It is necessary to keep in mind that the total levels of NT-proBNP (nonglycoNTproBNP+glycoNT-proBNP) seem to be much higher than those measured using the currently available assay system, though the clinical significance of measuring deglycosylated NT-proBNP remains to be determined (Figure 2).

It should be noted that the NT-proBNP assay system also cross-reacts with proBNP because of the common structure in their N-terminal regions (Figure 2). Because the plasma level of proBNP is much lower than that of NT-proBNP, the cross-reaction with proBNP in the NT-proBNP assay system may have little influence on the clinical interpretation of the NT-proBNP level.

\section{Regulation of proBNP Processing by O-Glycosylation of Its N-Terminal Region}

Numerous studies have reported on the mechanisms by which BNP gene expression is regulated in response to pathological conditions (reviewed in Kuwahara et a ${ }^{35}$ ). In addition to transcriptional regulation, post-translational regulation was recently shown to be involved in regulating the secretion of unprocessed proBNP and mature $\mathrm{BNP}_{1-32}$. However, the precise molecular mechanism governing post-translational cleavage of proBNP to $\mathrm{BNP}_{1-32}$ and NTproBNP in cardiomyocytes has not been fully elucidated. We recently clarified the significance of $O$-glycosylation of the $\mathrm{N}$-terminal region of proBNP, which is regulated via the miR-30-GALNTs axis, to proBNP processing (Figure 2). ${ }^{27}$

In humans, the $\mathrm{N}$-terminal segment of circulating proBNP is heavily glycosylated. ${ }^{\mathbf{2 6}, 29}$ Within the Golgi apparatus of human ventricular myocytes, proBNP is post-translationally glycosylated at 7 sites in the N-terminal region (Thr36, Ser37, Ser44, Thr48, Ser53, Thr58 and Thr71). ${ }^{29}$ The glycosylated proBNP is then transported to the trans-Golgi network, where it is enzymatically cleaved to mature $\mathrm{BNP}_{1-32}$ and NT-proBNP by furin. ${ }^{36-38}$ Semenov et al reported that $O$-glycosylation at Thr71 inhibits the cleavage of recombinant human proBNP in HEK293 cells, ${ }^{39}$ which suggests $O$-glycosylation at Thr71 is involved in regulating proBNP processing. On the other hand, another group reported that both wild-type (WT)-proBNP and a proBNP mutant in which Thr71 was substituted by alanine were processed similarly in HL-1 cells, a line of atrial cardiomyocytes. ${ }^{40}$ The significance of $O$-glycosylation of human proBNP to its processing and secretion in the heart thus remains unclear.

To clarify the contribution made by glycosylation in $\mathrm{N}$-terminal proBNP glycosylation to the regulation of proBNP processing and secretion, we examined the levels of human proBNP and $\mathrm{BNP}_{1-32}$ secreted into medium conditioned by neonatal rat ventricular myocytes (NRVMs) infected with lentiviral vectors harboring cDNA encoding WT or mutant human proBNP. WT-proBNP had 7 intact $O$-glycosylation sites, while the mutant proBNPs contained various combinations of $\geq 1$ mutant glycosylation sites that lacked the capacity for $O$-glycosylation. We measured proBNP and immunoreactive BNP, which means proBNP+ mature $\mathrm{BNP}_{1-32}$, in the conditioned medium as described earlier and calculated the proBNP/BNP ratio as a processing index. In medium conditioned by NRVMs expressing WTproBNP, the proBNP/BNP ratio was approximately 0.4 . This value is compatible with that in medium conditioned by human iPS-derived cardiomyocytes and also in plasma from the coronary sinus (CS) of HF patients. ${ }^{27}$ In medium conditioned by NRVMs expressing the aforementioned proBNP T71A mutant, the proBNP/BNP ratio was significantly lower than was obtained with WT-proBNP, which indicates $O$-glycosylation at $\mathrm{Thr} 71$ plays a key role in the processing of proBNP in ventricular myocytes, and in its subsequent secretion. Moreover, in the nonglyco-proBNP mutant, in which all 7 glycosylation sites were substituted with alanine, the proBNP/BNP ratio was markedly lower than that obtained with the T71A mutant. This suggests glycosylation sites other than Thr71 are also involved in regulating proBNP secretion. Further examination revealed that $O$-glycosylation at $\mathrm{Thr} 48$ also plays a pivotal role in the regulation of proBNP processing independently of Thr71. In addition, we found that $O$-glycosylation at each of those 2 sites independently and additively inhibits proBNP processing, while glycosylation at the other 5 sites (Thr36, Ser37, Ser44, Ser53, and Thr58) appears to support the inhibitory effect of glycosylation at Thr48 and Thr71, thereby increasing proBNP secretion from ventricular myocytes. ${ }^{27}$

Hypertrophic stimuli increase the proBNP/BNP ratio via glycosylation-dependent regulation of proBNP secretion. ${ }^{27}$ The N-acetylgalactosaminyltransferase (GalNac-T; GALNT) family is known to catalyze $O$-glycosylation and several GALNT family members are expressed in cardiac myocytes. Knocking down GALNT1 or 2 significantly reduces the proBNP/BNP ratio in medium conditioned by NRVMs expressing WT-proBNP. On the other hand, expression of both GALNT1 and 2 in NRVMs is significantly increased by hypertrophic stimuli, and in the failing hearts of rats. These data suggest GALNT-dependent regulation of $\mathrm{O}$-glycosylation is involved in the increased cardiac secre- 
tion of proBNP under pathological conditions. We also found that expression of miR-30, a microRNA abundantly expressed in cardiac myocytes, is decreased by hypertrophic stimuli in vitro and in pathologically remodeled hearts in both rodents and humans. ${ }^{41}$ Moreover, miR-30 negatively regulates expression of both GALNT1 and 2 in NRVMs and in mouse heart. ${ }^{27}$ All these data suggest that the miR30-GALNT1/2 pathway regulates proBNP/BNP ratio via $O$-glycosylation of proBNP in response to pathological conditions in the heart. Because the bioactivity of proBNP is much less than that of mature $\mathrm{BNP}_{1-32}$, increasing the proBNP/BNP ratio under pathological conditions weakens the cardioprotective effect, which then does not match the full effect estimated from the level of immunoreactive BNP. This can lead to decompensation and deterioration in HF (Figure 2).

\section{Clinical Significance of Evaluating BNP-Related Peptides}

Vodovar et $\mathrm{a}^{42}$ recently proposed a new compensatory mechanism in acute decompensated HF (ADHF) patients. They measured the degree of plasma proBNP glycosylation, $\mathrm{BNP}_{1-32}$, and NT-proBNP and showed that decreases in proBNP glycosylation parallel increases in the production of NT-proBNP and $\mathrm{BNP}_{1-32}$. This means that in ADHF patients, the compensatory mechanism to increase proBNP processing involves decreasing the degree of proBNP glycosylation at Thr71.

We evaluated levels of proBNP and BNP in plasma collected from the aortic root (AO) and CS of 53 consecutive patients with chronic HF. ${ }^{27}$ We divided these patients into 2 groups based on the median BNP level in the AO (highBNP group, low-BNP group). The ProBNP/BNP ratio in the $\mathrm{CS}$ and CS-AO, which is indicative of the transcardiac BNP production, were both significantly higher in the highBNP group. In addition, levels of cGMP/logBNP, which reflect the effect of endogenous BNP, were significantly lower in the high-BNP than in the low-BNP group. When the patients were divided into 2 groups based on the median proBNP/BNP ratio, cGMP/log BNP ratios were significantly lower in the high proBNP/BNP group than in the low proBNP/BNP group. This suggests the proBNP/BNP ratio is higher in patients with more severe HF, leading to a relative shortage of effective endogenous natriuretic peptide.

Takahama et $\mathrm{a}^{43}$ recently investigated the proBNP/BNP ratio in patients with ADHF. They found: (1) a relationship with ADHF severity, (2) changes in the ratio during treatment, and (3) a relationship with cGMP-generating activity. They measured plasma proBNP and $\mathrm{BNP}$ (proBNP+mature $\mathrm{BNP}_{1-32}$ or immunoreactive BNP) in ADHF patients on admission, 3 and 7 days after admission, and before discharge. On admission, the proBNP/BNP ratio was higher in patients with severe ADHF than in those with mild $\mathrm{ADHF}$, while the plasma cGMP/total BNP ratio, an index of the biological activity of BNP, was lower. Thus, in patients with mild ADHF, compensation for HF may occur via increased proBNP processing, leading to increases in mature $\mathrm{BNP}_{1-32}$ and activation of the $\mathrm{BNP} / \mathrm{cGMP}$ cascade. By contrast, this compensatory mechanism may be impaired in patients with severe ADHF.

Earlier, we mentioned that NT-proBNP is glycosylated and described how the currently available NT-proBNP assay system uses an antibody that recognizes the NT-proBNP region containing the glycosylation sites, which leads to underestimation of the true NT-proBNP level. Røsjø et $\mathrm{al}^{44}$ assessed the influence of glycosylation on the diagnostic and prognostic accuracy of NT-proBNP in patients with acute dyspnea. They evaluated and compared levels of NTproBNP measured using the Elecsys proBNP II (Roche Diagnostics) with and without deglycosylation. The patients with acute dyspnea $(n=309)$ were divided into HF and non-HF groups. NT-proBNP levels measured in samples pretreated with deglycosylation enzymes were markedly higher than in samples that were not pretreated (untreated NT-proBNP: HF 3,588ng/L, non-HF $360 \mathrm{ng} / \mathrm{L}$; treated NT-proBNP: HF 7,497 ng/L, non-HF 798 ng/L). During a median follow-up of 816 days, concentrations of both NT-proBNP and total NT-proBNP (i.e., NT-proBNP pretreated with deglycosylation enzymes) were predictive of death, as assessed with Kaplan-Meier plots, but the total NT-proBNP concentration was more closely associated with death during follow-up than the NT-proBNP concentration. The area under the curve to discriminate HF from non-HF with dyspnea was 0.871 (95\% CI $0.829-0.907)$ for pretreated, total NT-proBNP and 0.852 (0.807-0.907) for untreated NT-proBNP. These data suggested that NTproBNP after deglycosylation can be a more useful biomarker for HF than is NT-proBNP as currently evaluated..$^{44}$ Further testing of the clinical relevance of deglycosylated NT-proBNP in the patients with HF will be necessary, however.

\section{Acknowledgments}

We thank Mebae Kobayashi and Yukari Kubo for their excellent assistance with the manuscript.

\section{Funding}

This work was supported by grant-in-Aid for Scientific Research from the Japan Society for the promotion of Science 16K09498 (Y.N.), 15K09138 (T.N.), and 17H04174 (K.K.), and Research Grants from the Uehara Memorial Foundation and the Japan Heart Foundation (K.K.).

\section{Disclosures}

None.

\section{References}

1. Kangawa K, Matsuo H. Purification and complete amino acid sequence of alpha-human atrial natriuretic polypeptide (alphahANP). Biochem Biophys Res Commun 1984; 118: 131-139.

2. Sudoh T, Kangawa K, Minamino N, Matsuo H. A new natriuretic peptide in porcine brain. Nature 1988; 332: 78-81.

3. Sudoh T, Minamino N, Kangawa K, Matsuo H. C-type natriuretic peptide (CNP): A new member of natriuretic peptide family identified in porcine brain. Biochem Biophys Res Commun 1990; 168: $863-870$

4. Flynn TG, de Bold ML, de Bold AJ. The amino acid sequence of an atrial peptide with potent diuretic and natriuretic properties. Biochem Biophys Res Commun 1983; 117: 859-865.

5. de Bold AJ, Borenstein HB, Veress AT, Sonnenberg H. A rapid and potent natriuretic response to intravenous injection of atrial myocardial extract in rats. Life Sci 1981; 28: 89-94.

6. Yancy CW, Jessup M, Bozkurt B, Butler J, Casey DE Jr, Colvin MM, et al. 2017 ACC/AHA/HFSA Focused Update of the 2013 ACCF/AHA Guideline for the Management of Heart Failure: A Report of the American College of Cardiology/American Heart Association Task Force on Clinical Practice Guidelines and the Heart Failure Society of America. Circulation 2017; 136: e137e161.

7. Ponikowski P, Voors AA, Anker SD, Bueno H, Cleland JGF, Coats AJS, et al. 2016 ESC Guidelines for the diagnosis and treatment of acute and chronic heart failure: The Task Force for the diagnosis and treatment of acute and chronic heart failure of the European Society of Cardiology (ESC)Developed with the 
special contribution of the Heart Failure Association (HFA) of the ESC. Eur Heart J 2016; 37: 2129-2200.

8. Mukoyama M, Nakao K, Hosoda K, Suga S, Saito Y, Ogawa $\mathrm{Y}$, et al. Brain natriuretic peptide as a novel cardiac hormone in humans: Evidence for an exquisite dual natriuretic peptide system, atrial natriuretic peptide and brain natriuretic peptide. J Clin Invest 1991; 87: 1402-1412.

9. Yoshimura M, Yasue H, Okumura K, Ogawa H, Jougasaki M, Mukoyama M, et al. Different secretion patterns of atrial natriuretic peptide and brain natriuretic peptide in patients with congestive heart failure. Circulation 1993; 87: 464-469.

10. Morita E, Yasue H, Yoshimura M, Ogawa H, Jougasaki M, Matsumura T, et al. Increased plasma levels of brain natriuretic peptide in patients with acute myocardial infarction. Circulation 1993; 88: 82-91.

11. Nishikimi T, Yoshihara F, Morimoto A, Ishikawa K, Ishimitsu $\mathrm{T}$, Saito Y, et al. Relationship between left ventricular geometry and natriuretic peptide levels in essential hypertension. Hypertension 1996; 28: $22-30$.

12. Nagaya N, Nishikimi T, Okano Y, Uematsu M, Satoh T, Kyotani S, et al. Plasma brain natriuretic peptide levels increase in proportion to the extent of right ventricular dysfunction in pulmonary hypertension. J Am Coll Cardiol 1998; 31: 202-208.

13. Hawkridge AM, Heublein DM, Bergen HR 3rd, Cataliotti A, Burnett JC Jr, Muddiman DC. Quantitative mass spectral evidence for the absence of circulating brain natriuretic peptide (BNP-32) in severe human heart failure. Proc Natl Acad Sci USA 2005; 102: $17442-17447$.

14. Niederkofler EE, Kiernan UA, O'Rear J, Menon S, Saghir S, Protter AA, et al. Detection of endogenous B-type natriuretic peptide at very low concentrations in patients with heart failure. Circ Heart Fail 2008; 1: 258-264.

15. Miller WL, Phelps MA, Wood CM, Schellenberger U, Van Le A, Perichon R, et al. Comparison of mass spectrometry and clinical assay measurements of circulating fragments of B-type natriuretic peptide in patients with chronic heart failure. Circ Heart Fail 2011; 4: 355-360.

16. Vanderheyden $M$, Bartunek J, Goethals $M$, Verstreken $S$, Lambeir AM, De Meester I, et al. Dipeptidyl-peptidase IV and B-type natriuretic peptide: From bench to bedside. Clin Chem Lab Med 2009; 47: 248-252.

17. Lam CS, Burnett JC Jr, Costello-Boerrigter L, Rodeheffer RJ, Redfield MM. Alternate circulating pro-B-type natriuretic peptide and B-type natriuretic peptide forms in the general population. $J$ Am Coll Cardiol 2007; 49: 1193-1202.

18. Heublein DM, Huntley BK, Boerrigter G, Cataliotti A, Sandberg SM, Redfield MM, et al. Immunoreactivity and guanosine 3',5'-cyclic monophosphate activating actions of various molecular forms of human B-type natriuretic peptide. Hypertension 2007; 49: $1114-1119$.

19. Pankow K, Wang Y, Gembardt F, Krause E, Sun X, Krause G, et al. Successive action of meprin A and neprilysin catabolizes B-type natriuretic peptide. Circ Res 2007; 101: 875-882.

20. Waldo SW, Beede J, Isakson S, Villard-Saussine S, Fareh J, Clopton P, et al. Pro-B-type natriuretic peptide levels in acute decompensated heart failure. J Am Coll Cardiol 2008; 51: $1874-$ 1882.

21. Seferian KR, Tamm NN, Semenov AG, Mukharyamova KS, Tolstaya AA, Koshkina EV, et al. The brain natriuretic peptide (BNP) precursor is the major immunoreactive form of BNP in patients with heart failure. Clin Chem 2007; 53: 866-873.

22. Mogelvang R, Goetze JP, Schnohr P, Lange P, Sogaard P, Rehfeld JF, et al. Discriminating between cardiac and pulmonary dysfunction in the general population with dyspnea by plasma pro-B-type natriuretic peptide. J Am Coll Cardiol 2007; 50: $1694-1701$.

23. Giuliani I, Rieunier F, Larue C, Delagneau JF, Granier C, Pau B, et al. Assay for measurement of intact B-type natriuretic peptide prohormone in blood. Clin Chem 2006; 52: 1054-1061.

24. Nishikimi T, Minamino N, Ikeda M, Takeda Y, Tadokoro K, Shibasaki I, et al. Diversity of molecular forms of plasma brain natriuretic peptide in heart failure--different proBNP-108 to BNP-32 ratios in atrial and ventricular overload. Heart 2010; 96: $432-439$.

25. Nishikimi T, Okamoto H, Nakamura M, Ogawa N, Horii K, Nagata $K$, et al. Direct immunochemiluminescent assay for proBNP and total BNP in human plasma proBNP and total BNP levels in normal and heart failure. PLoS One 2013; 8: e53233.

26. Liang F, O'Rear J, Schellenberger U, Tai L, Lasecki M,
Schreiner GF, et al. Evidence for functional heterogeneity of circulating B-type natriuretic peptide. J Am Coll Cardiol 2007; 49: $1071-1078$.

27. Nakagawa $\mathrm{Y}$, Nishikimi T, Kuwahara K, Fujishima A, Oka S, Tsutamoto T, et al. MiR30-GALNT1/2 axis-mediated glycosylation contributes to the increased secretion of inactive human prohormone for brain natriuretic peptide (proBNP) from failing hearts. J Am Heart Assoc 2017; 6: e03601

28. Menon SG, Mills RM, Schellenberger U, Saqhir S, Protter AA. Clinical implications of defective B-type natriuretic peptide. Clin Cardiol 2009; 32: E36-E41.

29. Schellenberger U, O'Rear J, Guzzetta A, Jue RA, Protter AA, Pollitt NS. The precursor to B-type natriuretic peptide is an O-linked glycoprotein. Arch Biochem Biophys 2006; 451: e003601.

30. Seferian KR, Tamm NN, Semenov AG, Tolstaya AA, Koshkina EV, Krasnoselsky MI, et al. Immunodetection of glycosylated NT-proBNP circulating in human blood. Clin Chem 2008; 54: $866-873$.

31. Hammerer-Lercher A, Halfinger B, Sarg B, Mair J, Puschendorf $\mathrm{B}$, Griesmacher A, et al. Analysis of circulating forms of proBNP and NT-proBNP in patients with severe heart failure. Clin Chem 2008; 54: 858-865.

32. Nishikimi T, Ikeda M, Takeda Y, Ishimitsu T, Shibasaki I, Fukuda $\mathrm{H}$, et al. The effect of glycosylation on plasma N-terminal proBNP-76 levels in patients with heart or renal failure. Heart 2012; 98: $152-161$.

33. Luckenbill KN, Christenson RH, Jaffe AS, Mair J, OrdonezLlanos J, Pagani F, et al. Cross-reactivity of BNP, NT-proBNP, and proBNP in commercial BNP and NT-proBNP assays: Preliminary observations from the IFCC Committee for Standardization of Markers of Cardiac Damage. Clin Chem 2008; 54: 619-621.

34. Nakagawa Y, Nishikimi T, Kuwahara K, Yasuno S, Kinoshita H, Kuwabara Y, et al. The effects of super-flux (high performance) dialyzer on plasma glycosylated pro-B-type natriuretic peptide (proBNP) and glycosylated N-Terminal proBNP in end-stage renal disease patients on dialysis. PLoS One 2014; 9: e92314.

35. Kuwahara K, Nishikimi T, Nakao K. Transcriptional regulation of the fetal cardiac gene program. J Pharmacol Sci 2012; 119: 198-203.

36. Steinhelper ME. Structure, expression, and genomic mapping of the mouse natriuretic peptide type-B gene. Circ Res 1993; 72: 984-992.

37. Sawada Y, Inoue M, Kanda T, Sakamaki T, Tanaka S, Minamino $\mathrm{N}$, et al. Co-elevation of brain natriuretic peptide and proproteinprocessing endoprotease furin after myocardial infarction in rats. FEBS Lett 1997; 400: 177-182.

38. Nishikimi T, Nakagawa Y, Minamino N, Ikeda M, Tabei K, Fujishima A, et al. Pro-B-type natriuretic peptide is cleaved intracellularly: Impact of distance between O-glycosylation and cleavage sites. Am J Physiol Regul Integr Comp Physiol 2015; 309: R639-R649.

39. Semenov AG, Postnikov AB, Tamm NN, Seferian KR, Karpova NS, Bloshchitsyna MN, et al. Processing of pro-brain natriuretic peptide is suppressed by $\mathrm{O}$-glycosylation in the region close to the cleavage site. Clin Chem 2009; 55: 489-498.

40. Peng J, Jiang J, Wang W, Qi X, Sun XL, Wu Q. Glycosylation and processing of pro-B-type natriuretic peptide in cardiomyocytes. Biochem Biophys Res Commun 2011; 411: 593-598.

41. Duisters RF, Tijsen AJ, Schroen B, Leenders JJ, Lentink V, van der Made I, et al. miR-133 and miR-30 regulate connective tissue growth factor: Implications for a role of microRNAs in myocardial matrix remodeling. Circ Res 2009; 104: 170-178, 6p following 178 .

42. Vodovar N, Seronde MF, Laribi S, Gayat E, Lassus J, Boukef $\mathrm{R}$, et al. Post-translational modifications enhance NT-proBNP and BNP production in acute decompensated heart failure. Eur Heart J 2014; 35: 3434-3441.

43. Takahama H, Takashio S, Nishikimi T, Hayashi T, NagaiOkatani C, Nakagawa Y, et al. Ratio of pro-B-type natriuretic peptide (BNP) to total BNP is decreased in mild, but not severe, acute decompensated heart failure patients: A novel compensatory mechanism for acute heart failure. Int J Cardiol 2018; 258: $165-171$.

44. Røsjø H, Dahl MB, Jorgensen M, Roysland R, Brynildsen J, Cataliotti A, et al. Influence of glycosylation on diagnostic and prognostic accuracy of $\mathrm{N}$-terminal pro-B-type natriuretic peptide in acute dyspnea: Data from the Akershus Cardiac Examination 2 Study. Clin Chem 2015; 61: 1087-1097. 